\title{
Osteocalcin expression of platelet-rich fibrin (PRF) and platelet- rich plasma (PRP) added with hydroxyapatite (HA) in rabbit's post extraction tooth sockets
}

\author{
Meta Maulida Damayanti ${ }^{*}$, Bethy Suryawathy Hernowo ${ }^{2}$, Susi Susanah ${ }^{3}$ \\ ${ }^{1}$ Basic Medical Science Magister Program, Faculty of Medicine Universitas Padjadjaran, Indonesia \\ 2Department of Pathology Anatomy, Faculty of Medicine Universitas Padjadjaran, Indonesia \\ ${ }^{3}$ Division of Hematology and Oncology, Department of Child Health, Hasan Sadikin Hospital, Indonesia
}

\section{ABSTRACT}

Introduction: Platelets play an important role in wound healing because it is a reservoir for growth factors and cytokines which is important in bone regeneration and soft tissue healing. The purpose of this study was to compare the use of scaffolds in platelet-rich fibrin (PRF) and platelet-rich plasma (PRP) which added with hydroxyapatite (HA) in the socket healing process after tooth extraction in the value of regenerating an alveolar bone tissue. Methods: The research was conducted at biomedical laboratory Bandung Islamic University. Eighteen rabbits (Oryctolagus cuniculus) with extracted anterior and inferior teeth were divided into 2 treatment groups and 3 observation times. The tooth socket is filled with PRF (Group 1) and PRP + HA (Group 2). The observation was conducted on Day 3, Day 7 and Day 14. Immunoexpression Osteocalcin was performed to assess the healing process of alveolar bone. Data was analyzed with the SPSS software program. Analysis of normality data by Shapiro-Wilk test, homogeneity of variance with Levene's test and comparison between treatment groups with the Chisquare test. Results: Group 1 shown the average score was higher than in Group 2 with a strong category of $72.2 \%$ for Group 1 and $56.6 \%$ for Group 2. Based on statistically, there was no difference in osteocalcin immunoexpression between Group 1 and Group 2 with the p-value $>0.05$. Conclusion: Regeneration of rabbit's alveolar bone tissue by application of PRF and PRP plus HA as scaffolds have results was similar. The use of PRF in post-extraction wound recovery is a better choice because it has an easy procedure and lower cost.

Keywords: Hydroxyapatite (HA), osteocalcin expression, platelet-rich fibrin (PRF), platelet-rich plasma (PRP), tooth socket.

p-ISSN: 1979-0201; e-ISSN: 2549-6212; Available from: http://jurnal.unpad.ac.id/pjd/article/view/24848

DOI: $10.24198 /$ pjd.vol32no3.24848

Submission: Nov 28, 2019; Accepted: Nov 29, 2020; Published online: Nov 30, 2020

"Corresponding author: Meta Maulida Damayanti, Basic Medical Science Magister Program, Faculty of Medicine Universitas Padjadjaran, Indonesia. 38, Jalan Professor Eyckman, Bandung, Indonesia, 40132. Phone: +6281395014778; e-mail: meta md@unisba.ac.id 


\section{INTRODUCTION}

Platelet-rich plasma (PRP) and platelet-rich fibrin (PRF) are autologous platelets concentrates made from the patient's blood. Recent research is being focused on developing alternative therapies that are easily prepared, non-toxic or biocompatible with living tissue and are economical thus able to produce the release of local growth factors that accelerate the healing of soft and hard tissues. Platelets play an important role in wound healing, that begins with the formation of blood clots after tissue injury in tooth extraction causes platelet adherence and aggregation that supports thrombin and fibrin formation. Besides, there is a release of certain substances from platelets that encourage tissue repair, angiogenesis, inflammation, and immune responses. ${ }^{1}$

Tooth sockets contain hard and soft tissue which improves with many speeds in the healing process. ${ }^{2}$ These local changes appear to close socket wounds and restore tissue homeostasis, and referred to as socket healing. The socket healing process can be divided into three consecutive phases which often overlapped, namely inflammation; proliferative; and remodeling. ${ }^{3}$ Platelets containing biologically active proteins and binding of proteins secreted in fibrin mesh or developing into the extracellular matrix that can create chemotaxis gradients that support stem cell recruitment, stimulate cell migration, differentiation, and promote improvement or cell repair. Thus, the use of autologous platelet concentrates is a promising application in the area of periodontal and alveolar tissue regeneration that can be used in clinical situations that require rapid healing. ${ }^{1,4}$

PRF has been frequently used in regenerative dentistry, with the assumption that the level of concentrated growth factors is proportional to the concentration of platelets. Platelet counts in PRF are generally determined indirectly by platelet counts in other liquid fractions. ${ }^{5,6}$ PRF, explained by Choukroun et al. ${ }^{7}$, was first introduced into clinical applications in maxillofacial surgery and oral implants in Southern Europe. PRF is a new generation of platelet concentrate technique that allows to obtain a fiber membrane enriched with platelets and growth factors, starting from taking anticoagulant-free blood. ${ }^{7,8}$
Besides the use of PRF, many studies support the use of autologous PRP in clinical practice, including for soft tissue injuries, fractures, tooth extraction, dental implants, periapical lesions, periodontal surgery, sinus removal, and oral/ maxillofacial surgery. Since that growth factors play an important role in the regeneration of soft and hard tissues, the proposed mechanism for healing results that is accelerated by PRP is through the release of critical growth factors by activated platelets.9-12 PRP coupled with hydroxyapatite will result in activated platelets being trapped in fibrin tissue; in the matrix, and platelets secrete bioactive substances that diffuse into the surrounding tissue. PRP is made from the patient's blood; various manufacturing techniques have many differences in cell number and concentration of growth factors. Growth factors alone in PRP do not increase bone production. The use of autologous grafts is the gold standard for filling biomaterial bone defects. After extraction of the tooth, the socket becomes deformed. . $^{9-10}$

Hydroxyapatite is the main mineral component of bone. Synthetic hydroxyapatite has distributed in various forms, the primary is as non-absorbable porous, dense or solid that can't be absorbed, and absorbable forms (non-ceramic, porous). ${ }^{13}$ Platelets play an important role in hemostasis and are a natural source of growth factors. Amixture of particulate hydroxyapatite and platelet-rich plasma can build an osteoinductive effect during the bone healing stage. ${ }^{14}$ This study aimed to evaluate the use of platelet-rich fibrin and platelet-rich plasma plus hydroxyapatite in the treatment of post-extraction tooth sockets to produce fast, economical technique and good bone healing.

\section{METHODS}

The research was conducted at biomedical laboratory Universitas Islam Bandung. This study is a true experiment with a randomized complete design. Eighteen rabbits (Oryctolagus cuniculus) with extracted anterior inferior regions of tooth were randomly selected according to the study criteria. This study uses 2 treatment groups and 3 observation times. For group 1, the tooth extraction socket was filled with PRF, and for group 2 with PRP+HA. The observation was conducted on 
$3^{\text {rd }}$ day, $7^{\text {th }}$ day, and $14^{\text {th }}$ day based on the healing process phase. Biopsy of periodontal and alveolar tissue of the socket performs in each observation time.

All specimens were fixed in $10 \%$ buffered neutral formalin and embedded in paraffin. Specimens in paraffin blocks were cut to $4 \mu \mathrm{m}$ sections thick and mounted on advanced adhesive microscope slides with two-section slides per specimen were prepared. Sections were then deparaffinized in xylene and hydrated in graded alcohols and continued with immunohistochemistry preparations. Immunohistochemistry uses Abcam osteocalcin, polyclonal antibody products.

Slides are then evaluated under a light microscope at 100x and 400x magnification. Immunoexpression of Osteocalcin is regarded as positive when the stroma around colored by brown, negative intensity/no immunoreactivity $(--)$, weak $(+)$, medium $(++)$ or strong staining
$(+++) .{ }^{15-18}$

Data was analysed with the SPSS software program, and comparison between treatment groups was analysed with the Chi-square test. This research has passed the ethics committee issued by Universitas Padjadjaran No. 132/UN6.C1.3.2/ KEPK/PN/2017. Analysis of normality data by Shapiro-Wilk test, homogeneity of variance with Levene's test

\section{RESULTS}

The data normality was analysed using the Shapiro-Wilk test (Table 1), which showed that the histoscore was constant in th 3 rd day of observation. The homogeneity of variance was analysed with Levene's test to determine the mean of groups in homogeneous subsets (Table 2 ), while the comparison between treatment groups was analysed using the chi-square test (Table 3 ).

Table 1. Normality test results (Shapiro-Wilk)

\begin{tabular}{lcccc}
\hline & Treatment group & Shapiro-Wilk \\
\hline \multirow{3}{*}{ Histocore } & & Statistic & df & Sig. \\
& 1 & 0.640 & 6 & 0.004 \\
& 2 & 0.866 & 6 & 0.212 \\
\hline
\end{tabular}

Table 2. Homogeneity of variance test results (Levene's test)

\begin{tabular}{cccccc}
\hline & Treatment group & Levene's statistic & df1 & df2 & Sig. \\
\hline \multirow{2}{*}{ Histocore } & 1 & 2.371 & 2 & 15 & 0.127 \\
& 2 & 8.248 & 2 & 15 & 0.004 \\
\hline
\end{tabular}

Osteocalcin expression with different scaffolds administration in tooth sockets was shown in both groups. During the experiment, there were no dropped out or dead animals.

Table 3. Differences in osteocalcin scores between the PRF Group and PRP+HA with the chi-square test

\begin{tabular}{|c|c|c|c|c|c|c|}
\hline & \multicolumn{4}{|c|}{ Immunoexpression osteocalcin } & \multirow[b]{2}{*}{$\begin{array}{l}\text { Total } \\
\text { n (\%) }\end{array}$} & \multirow[b]{2}{*}{ P-value } \\
\hline & $\begin{array}{c}\text { Negative } \\
\text { n (\%) }\end{array}$ & $\begin{array}{l}\text { Weak } \\
\mathrm{n}(\%)\end{array}$ & $\begin{array}{c}\text { Medium } \\
\mathrm{n}(\%)\end{array}$ & $\begin{array}{c}\text { Strong } \\
\mathrm{n}(\%)\end{array}$ & & \\
\hline $\begin{array}{c}\text { Group } \\
1 \\
2\end{array}$ & $\begin{array}{l}1(5.6) \\
1(5.6)\end{array}$ & $\begin{array}{c}1(5.6) \\
2(11.1)\end{array}$ & $\begin{array}{l}3(16.7) \\
5(27.8)\end{array}$ & $\begin{array}{l}13(72.2) \\
10(55.6)\end{array}$ & $\begin{array}{l}18(100) \\
18(100)\end{array}$ & 0.775 \\
\hline
\end{tabular}

Group 1 has a higher average score compared to group 2, with a strong category of $72.2 \%$ for G1 and $56.6 \%$ for G2 (Table 1 ). But statistically, it can be concluded that there is no difference in osteocalcin expression between the group 1 and 2 with P-value 0.775 .

Histological examination was taken from the tooth socket showing the formation of new bone by immunoexpression of osteocalcin. Histological clinical findings indicate that the extraction socket of teeth filled with PRF and PRP+HA provides a viable alternative therapy to accelerate wounds healing, namely the regeneration of alveolar bone.

The results of difference in osteocalcin immunoexpression at each observation time are 
summarized in Table 2. The $3^{\text {rd }}$ day of administering shows relatively weak staining (brown lightcolored) on osteocytes (OCT), osteoblasts (OB), and extracellular matrix $(\mathrm{ECM})$. On the $7^{\text {th }}$ day of administering showed a medium intensity (colored brown) in osteocytes (OCT), osteoblasts $(\mathrm{OB})$, and extracellular matrix $(\mathrm{ECM})$, while immunoexpression of osteocalcin on the $14^{\text {th }}$ day of administering shows the strong staining (dark brown colored) on osteocytes (OCT), osteoblasts $(\mathrm{OB})$, and extracellular matrix (ECM). An increase in intensity and distribution during the observation period indicates an increase in bone tissue healing every time, but the differentiation scores of both groups was not significant.
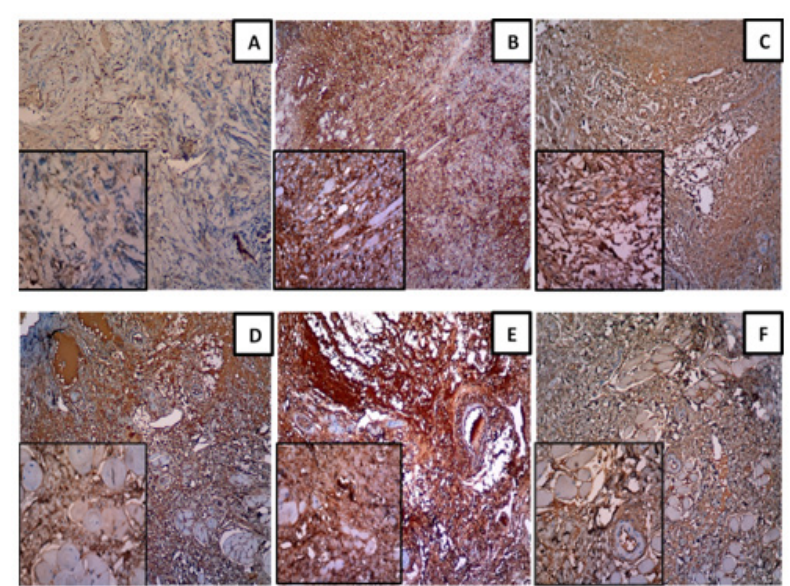

Figure 1. Immunoexpression of osteocalcin on 100x and 400x magnification. A. is group 1 on day 3 , B. is group 1 on day 7, C. is group 1 on day $14, D$. is group 2 on day $3, E$. is group 2 on day 7 , and $F$. is group 2 on day 14 .

Table 2. Group 1 and 2 differences are based on observation time

\begin{tabular}{cc}
\multicolumn{2}{c}{ observation time } \\
\hline Group treatment & P-value osteocalcin \\
\hline 1 & 0,156 \\
2 & 0,156 \\
\hline
\end{tabular}

\section{DISCUSSION}

Tissue engineering uses PRP and PRF as growth factors and a combination of the two has been suggested as an alternative to bone grafts in recent decades using animal studies with different platelet products and their combination with various substances such as hydroxyapatite for regenerating bone. Different platelets preparation techniques have been known to produce very different cell counts, namely platelets and leukocytes as well as varying levels of growth factors. In addition to the platelets protocol, modification of its use will have different results. The use of additional scaffold from hydroxyapatite should make regeneration faster, but the results are no different. ${ }^{24}$

PRF is an immune and platelet concentrate containing all constituents of a blood sample that supports healing and immunity in a single fibrin membrane. However, the information that is available today is limited to healing in histological socket teeth on the use of PRF. Alzahrani et al., states that Radiographic analysis of socket, the mean RBF was significantly higher at the expression of osteocalcin in tooth extraction filled with PRF in the test group than the control group at all time intervals. ${ }^{19}$

In this study, the effect of platelet derivatives on wound healing has led to the idea of its use in various oral disorders. In the comparison between PRF and PRP + HA, PRF shows a slightly higher stimulation role in periodontal regeneration, but this is not significant because both have a good growth factor and scaffold component in tissue regeneration. In contrast to research conducted by that the use of PRP appears to be better in wound healing. Platelet cells play a key role in recent research due to the effects of various growth factors and cytokines with healing properties. PRP with $72 \%$, then PRGF (13.5\%) and PRF (12\%) were the most interesting platelet products in the Iranian study. ${ }^{24}$

It is known that the blood component is the main key in the process of wound healing. The fibrin matrix binds to the bioactive molecule and regulates the time and space in the microenvironment that will drive the healing process. As a biomimetic approach, the use of blood derivatives in regenerative strategies has developed as a source of several therapeutic biomolecules. ${ }^{6}$ The clinical experience that both the use of PRP in various medical fields has prompted researchers to optimize the exploration of clinical opportunities for PRP therapy. PRP is safe but we must make it more effective. The increasing variety of formulations and presentations enriches the field of PRP research and offers hope for improving clinical indications. ${ }^{20} \mathrm{Hydroxyapatite}$ is the choiced of ceramic, producing predictable short and long term results. The graft material acts as a biocompatible material in the gingival 
tissue, and when absorbed, it acts as a mineral reservoir and helps bone formation through osteoconductive mechanisms, producing clinically acceptable responses to increase the potential of the graft regenerative used. ${ }^{21}$

Mechanism of the healing process released facilitated by PRF and PRP+HA showed the same result: activated platelets that are trapped in fibrin tissue; in the matrix, platelets secrete bioactive substances that diffuse into the surrounding tissue. Autologous bone grafts are the gold standard clinical material for bone regeneration in terms of osteoconduction and osteoinduction. PRP causes rapid bone maturation and increased bone density. Thus, augmentation of extraction sockets with autogenic hydroxyapatite particles and PRP will be a promising method for healing the tooth and alveolar sockets after extraction. ${ }^{22}$ The PRF special texture and also has a logical function from the beginning, was also unchanged, and all the technical requirements that can be supported by regulation, fast and high quality. ${ }^{23}$

Therefore, it is suggested that further studies with better materials and techniques comparing the efficacy of PRF and PRP with bioabsorbable membranes be carried out to assess their comparative clinical efficacy in preservation of the extraction socket. Moreover, a possible limitation of this study was the short follow-up of socket healing, which lasted only 14 days. Therefore, further long-term studies with standard methodologies are needed.

From a clinical perspective, the use of autologous PRF and PRP in the healing socket and surgical site is recommended to improve bone healing and minimize resorption. ${ }^{19}$ Explanation of the reasons for the lack of additive PRP effects will be speculative due to the limitations of this study namely small sample size, shorter followup period, absence of other parameters such as radiography. ${ }^{21}$ In future research, it must be carried out to link the clinical results of PRF with its biological mechanism that opens up this new application of autologous platelet concentrates. There are only limited studies in the literature on the effects of PRF on cell proliferation and other biological effects. Therefore, further research must be carried out that opens up new strategies for the use of these platelet concentrates. ${ }^{1}$ PRF usage, when compared with PRP+HA, has advantages in terms of the economical technique, lower cost, and the same healing result.

\section{CONCLUSION}

Regeneration of rabbit's alveolar bone tissue by application of PRF and PRP plus HA as scaffolds have results was similar. The use of PRF in postextraction wound recovery is a better choice because it has an easy procedure and lower cost. Autogenous fibrin-rich platelets and plateletrich plasma plus hydroxyapatite have proven to be effective in healing alveolar sockets after extraction. This approach is expected to provide promising clinical results in maintaining alveolar socket structure and function after extraction.

\section{REFERENCES}

1. Chandran P, Sivadas A. Platelet-rich fibrin: Its role in periodontal regeneration. Saudi J Dent Res. 2014; 5(2): 117-22. DOI: 10.1016/j. ksujds.2013.09.001

2. Srinivas B, Das P, Rana MM, Qureshi AQ, Vaidya $K C$, Raziuddin SJA. Wound healing and bone regeneration in post-extraction sockets with and without platelet-rich fibrin. Ann Maxillofac Surg. 2018; 8(1): 28-34. DOI: 10.4103/ams. ams $153 \quad 17$

3. Araújo MG, Silva CO, Misawa M, Sukekava F. Alveolar socket healing: What can we learn? Periodontol 2000. 2015; 68(1): 122-34. DOI: 10.1111/prd.12082

4. Su NY, Yang LC, Chang YC. Platelet-rich fibrin is the first-line treatment option for periodontal regeneration. J Dent Sci. 2017; 12(3): 203-4. DOI : $10.1016 / j . j d s .2017 .02 .005$

5. Kitamura Y, Watanabe T, Nakamura M, Isobe K, Kawabata H, Uematsu K, et al. Platelet counts in insoluble platelet-rich fibrin clots: A direct method for accurate determination. Front Bioeng Biotechnol. 2018; 6: 4. DOI: 10.3389/ fbioe.2018.00004

6. Bucur M, Constantin C, Neagu M, Zurac S, Dinca O, Vladan C, et al. Alveolar blood clots and platelet-rich fibrin induce in vitro fibroblast proliferation and migration. Exp Ther Med. 2019; 17(2): 982-89. DOI: 10.3892/ etm.2018.7063

7. Choukroun J, Ghanaati S. Reduction of relative 
centrifugation force within injectable plateletrich-fibrin (PRF) concentrates advances patients' own inflammatory cells, platelets and growth factors: The first introduction to the low speed centrifugation concept. Eur $\mathrm{J}$ Trauma Emerg Surg. 2018. 44(1): 87-95. DOI: 10.1007/s00068-017-0767-9

8. Baslarli O, Tumer C, Ugur O, Vatankulu B. Evaluation of osteoblastic activity in extraction sockets treated with platelet-rich fibrin. Med Oral Patol Oral Cir Bucal. 2015; 20(1): e111-6. DOI: 10.4317/medoral.19999

9. Davis VL, Abukabda AB, Radio NM, WittEnderby PA, Clafshenkel WP, Cairone JV, et al. Platelet-rich preparations to improve healing part I: Workable options for every size practice. J Oral Implantol. 2014; 40(4): 50010. DOI: 10.1563/AAID-JOI-D-12-00104

10. Marques LF, Stessuk T, Camargo ICC, Sabeh Junior N, dos Santos L, Ribeiro-Paes JT. Plateletrich plasma (PRP): Methodological aspects and clinical applications. Platelets. 2015; 26(2): 101-13. DOI: 10.3109/09537104.2014.881991

11. Monga P, Grover R, Mahajan P, Keshav V, Singh $N$, Singh $G$. A comparative clinical study to evaluate the healing of large periapical lesions using platelet-rich fibrin and hydroxyapatite. Endodontology. 2016; 28(1): 27. DOI: 10.4103/0970-7212.184336.

12. Thanikasalam M, Ahamed S, Narayana SS, Bhavani S, Rajaraman G. Evaluation of healing after periapical surgery using platelet-rich fibrin and nanocrystalline hydroxyapatite with collagen in combination with platelet-rich fibrin. Endodontology. 2018; 30(1): 25. DOI: 10.4103/endo.endo_55_17.

13. Singh J, Takhar RK, Bhatia A, Goel A. Bone graft materials: dental aspects. J Nov Res Healthc Nurs. 2016; 3: 99-103.

14. Saleh A, Abd el Rehim S, Kawana K, Osman S. Effect of autogenous dentin graft combined with platelet rich plasma on alveolar bone healing after tooth extraction in rabbits. Alex Den J. 2018; 43(1): 6-10. DOI: 10.21608/ ADJALEXU.2018.57588.

15. Antonino A, Maria E L, Bianca P, Campisi G.
Platelet-rich plasma (PRP) in dental and oral surgery: from wound healing to bone regeneration. Immun Ageing. 2013; 10:23. DOI: 10.1186/1742-4933-10-23.

16. Yu-Chao C, Kuo-Chin W, Jiing-Huei Z. Clinical application of platelet-rich fibrin as the sole grafting material in periodontal intrabony defects. J Den Sci. 2011; 6. DOI: 10.1016/j. jds.2011.05.010.

17. Zhao J H, Tsai C H, Chang Y C. Clinical and histologic evaluations of healing in an extraction socket filled with platelet-rich fibrin. J Den Sci. 2011; 6(2): 116-22. DOI: 10.1016/j.jds.2011.03.004.

18. Alzahrani A A; Murriky A, Shafik S. Influence of platelet rich fibrin on post-extraction socket healing: a clinical and radiographic study. Saudi Den J. 2017; 29(4): 149-55. DOI: 10.1016/j.sdentj.2017.07.003.

19. Andia I; Maffulli N. A contemporary view of platelet-rich plasma therapies: moving toward refined clinical protocols and precise indications. Reg Med. 2018; 13(06): 717-28. DOI: 10.2217/rme-2018-0042.

20. Bhatia G, Khatri M, Bansal M, Saxena S, Agarwal V, Kumar A. A comparative evaluation of porous hydroxyapatite bone graft with and without platelet-rich plasma in the treatment of periodontal intrabony osseous defects: a clinico-radiographic study. Indian J Den Sci. 2018; 10(2): 72. 10.4103/IJDS.IJDS_5_18.

21. Wang W, Yeung KWK. Bone grafts and biomaterials substitutes for bone defect repair: a review. Bioact Mat. 2017; 2(4): 22447. DOI: $10.1016 / j$.bioactmat.2017.05.007.

22. Giannini S, Cielo A, Bonanome L, Rastelli C, Derla C, Corpaci F, Falisi G. Comparison between PRP, PRGFAnd PRF: lights and shadows in three similar but different protocols. Eur Rev Med Pharmacol Sci. 2015;19(6):927-30.

23. Seyed Ahmad Raeissadat, Marzieh Babaee, Seyed Mansour Rayegani, Zahra Hashemi, Amir Ali Hamidieh, Parviz Mojgani, et al. An overview of platelet products (PRP, PRGF, PRF, etc.) in the Iranian studies. Fut Sci. 2017;3(4). DOI: 10.4155/fsoa-2017-0045. 